\title{
Safety and affordability of an elective Saturday list at Pietersburg Hospital, Limpopo, South Africa
}

\author{
M M Z U Bhuiyan, MBBS, DTH, FRCSG, MMed; R Mavhungu, BSc (Med Sci) \\ Department of General Surgery, Pietersburg Hospital and Faculty of Health Sciences, University of Limpopo, Turfloop, South Africa
}

Corresponding author: M M U Bhuiyan (bhuiyanmirza@gmail.com)

\begin{abstract}
Background. The backlog of patients waiting for operations continues to be a problem in many public hospitals in South Africa (SA), with elective surgery procedures being postponed for up to 2 years.

Objective. To determine the rate of death in hospital or out of hospital within 30 days of an elective procedure performed on a Saturday, and to determine the cost incurred by paying staff members who perform these operations.

Method. A prospective, observational descriptive cohort study of all patients undergoing inpatient general surgery operations during weekdays and weekends between 1 September 2015 and 31 August 2016 (1 year) at Pietersburg Hospital (PBH), Limpopo, SA. Microsoft Excel 2010 (Microsoft, USA) was used to analyse and derive descriptive statistics. The finance department at the hospital calculated the overtime pay for theatre staff who operated on Saturdays.

Results. The study included 1352 operations (607 elective and 745 emergency procedures). Saturday elective operations contributed 133/607 (22\%), and the rate of death for these operations was $1.5 \%$. The most common procedures performed on a Saturday were hernia repair and amputation. The cost for 8 hours of work on a Saturday was ZAR13 900, amounting to a total of ZAR333 600 for 24 Saturdays.

Conclusion. Performing minor surgery on a Saturday had a mortality rate of $1.5 \%$, and a theatre staff cost of $\sim$ ZAR2 317 per patient, excluding surgeons' fees. If surgeons were to be paid the costs would be ZAR3 450 per patient.
\end{abstract}

S Afr Med J 2018;108(2):123-125. DOI:10.7196/SAMJ.2018.v108i2.12426

Five billion people worldwide do not have access to safe, affordable surgical and anaesthetic care, lack of access being worst in low- and middle-income countries, where 9 of 10 people cannot access basic surgical care - 143 million additional surgical procedures are needed in such countries each year to save lives and prevent disability. ${ }^{[1]}$

The backlog of patients waiting for operations continues to be a problem in many public hospitals in South Africa (SA), with patients waiting up to 2 years for elective operations. ${ }^{[2]}$ The waiting period in our hospital is currently $4-6$ months for general surgery, with variation depending on the allocated team. Pietersburg Hospital $(\mathrm{PBH})$ is one of two tertiary hospitals serving 5.5 million people in Limpopo Province, SA. Most of the patients are from rural communities and entirely dependent on public hospitals for their healthcare needs. The regional and district hospitals are not well staffed to provide for patients after hours.

Delayed elective surgery leads to increased morbidity, mortality and frustration for the patients, and is caused by a number of factors, e.g. shortage of surgeons, lack of theatre space, and lack of well-staffed district and regional hospitals. Cancellation of elective operations contributes to a larger proportion of the delay. The cancellation rate of elective operations was $44.5 \%$ at $\mathrm{PBH}$ in 2014 , with $65 \%$ due to emergency bookings during a weekday because of unavailability of an emergency theatre. ${ }^{[3]}$ The cancellation cost is high for the patient and the hospital; the cost of a single cancellation at a tertiary hospital was ZAR25 000. ${ }^{[3]}$

To maximise theatre use some surgeons at PBH introduced general surgery operations on a Saturday, without receiving extra remuneration. Theatre operations require assistance from an anaesthetist, a central sterile services department nurse, a porter, and cleaners. They all agreed to assist on a Saturday, provided they received overtime pay.
The weekend effect on mortality is well documented in the literature, with several studies indicating adverse consequences of weekend hospitalisation, ${ }^{[4-11]}$ while a few studies did not find such effects. ${ }^{[12,13]}$ The studies compared the outcome of elective procedures performed during the week with those performed over the weekend.

Our literature review could not find any studies on the death rate for elective procedures performed on a Saturday and the cost analysis of overtime pay for staff members performing such operations.

\section{Objective}

The objective of the study was to determine the rate of death in hospital or out of hospital within 30 days of an elective procedure performed on a Saturday and the cost incurred by paying staff members performing these operations.

\section{Method}

This was a 1-year hospital-based, prospective, observational, descriptive cohort study of all patients (adults and children) undergoing operations in the Department of General Surgery, $\mathrm{PBH}$. Permission to conduct the study was received from the clinical executive director and the chief executive officer of the hospital. The information was collected prospectively from 1 September 2015 to 31 August 2016, and was recorded using a data collection sheet specifically designed for the study. All patients undergoing general elective and emergency surgical procedures on weekdays and weekends during this period were included. For selection on the Saturday list, the patient had to have an American Society of Anesthesiologists (ASA) score of grade 1 or 2 and, in some cases, grade 3. Selected cases of amputation of the leg because of gangrene were included. We excluded operations that usually last $>90$ minutes, such as thyroidectomy and vascular procedures. The theatre register 
was used as the starting point for data collection. The patients were followed up postoperatively from day 1 to day 30 . The documented variables included initials of the patient, file number, contact number, age, gender, date of operation, nature of operation (elective or emergency), type of procedure, time of operation (weekday or after hours/weekend), postoperative complication/s, and status at the time of hospital discharge (alive/dead) and 30 days postoperatively (alive/dead). The status of those who were discharged alive before day 30 after the operation was checked on their return for scheduled follow-up at the surgical outpatient department. If the patient was discharged from the follow-up visit before day 30 , they or their next of kin were contacted telephonically to determine their postoperative day 30 status.

Elective surgery was divided into Saturday and weekday operations. Saturday elective operations were performed between $07 \mathrm{~h} 30$ and $16 \mathrm{~h} 00$, whereas weekday elective operations were performed between $07 \mathrm{~h} 30$ and $16 \mathrm{~h} 00$ from Monday to Friday (excluding holidays). Emergency operations were divided into those performed during working hours (07h30 - 16h00, Monday - Friday) and after hours, including weekends (Saturday and Sunday) and public holidays.

\section{Data analysis}

Data were captured and analysed using Microsoft Excel 2010 (Microsoft, USA). Continuous variables were described as medians and ranges, while categorical variables were described as proportions.

\section{Costs}

The overtime payment calculation for staff performing operations on a Saturday was obtained from the finance department of PBH. The cost of 8 hours' work for an anaesthetist was ZAR3 400 per Saturday. The combined overtime financial cost for 6 nurses, 1 cleaner and 1 porter was ZAR10 500 for 8 hours on a Saturday.

\section{Results}

During the study period (1 September 2015 - 31 August 2016), 1352 operations were performed, comprising elective $(n=607)$ and emergency $(n=745)$ procedures. The age range of the study group was 1 - 93 (median 37, mode 30) years. The proportion of males and females was $68 \%$ and $32 \%$, respectively. The most common procedures performed on a Saturday were hernia repair and amputation (Table 1). As we did not have an emergency theatre, some semi-urgent patients, e.g. those with gangrene of the foot, were booked on the elective list

\begin{tabular}{ll} 
Table 1. Operations performed on Saturdays (N=133) & \\
\hline Procedure & $n$ \\
\hline Hernia repair & 39 \\
Amputation & 20 \\
Excision of mass & 12 \\
Mastectomy and excision of breast mass & 17 \\
Colostomy closure and diverting colostomy & 12 \\
Gastrostomy & 5 \\
Mini laparotomy and biopsy & 4 \\
Skin graft & 3 \\
Debridement & 3 \\
Arteriovenous fistula & 2 \\
Fistulectomy & 2 \\
Laparotomy & 2 \\
Other (e.g.melanoma excision, scalp aneurysm repair, & 12 \\
hydrocelectomy, insertion of port, drainage of sub- & \\
diaphragmatic abscess, pelvic abscess) & \\
&
\end{tabular}

for amputations. The most common procedure performed during weekdays and Saturdays was hernia repair.

Of the 607 elective operations, 133 were performed on Saturdays and 474 during weekdays, with an overall death rate of $1.81 \%$. Saturday elective operations comprised $22 \%$ of the total elective procedures. The rate of death for Saturday operations was $1.5 \%$ $(n=2)$, and $1.9 \%(n=9)$ of patients operated on a weekday died within 30 days after the procedure. Patients with the following conditions died after a Saturday operation: gangrene of the foot, with amputation of the leg; chronic abdominal distension; and tuberculosis of the peritoneal cavity (revealed after a diagnostic laparotomy). Postoperative complications included wound sepsis in 4 cases and deep-vein thrombosis in 1 case.

A total of 745 emergency operations were performed, 209 during official hours and 536 after hours, with an overall death rate of $5.1 \%$. The overall mortality for elective and emergency operations was $3.63 \%$.

\section{Costs}

The financial implications with regard to staff for 8 hours' work on a single Saturday was ZAR13 900, which comprised the anaesthetist (ZAR3 400) and the rest of the staff (ZAR10 500). The total financial cost for the 24 Saturdays amounted to ZAR 333600 .

\section{Discussion}

PBH is the only hospital in Limpopo that provides a 24-hour general surgery service. ${ }^{[3]}$ The 500 -bed hospital, serving 5.5 million people in Limpopo, has 6 operating theatres that cater for 9 disciplines. Despite years of trying to acquire an emergency theatre, there was no daytime emergency theatre for general surgery during the study period. The current infrastructure cannot be extended to create space for an emergency theatre. However, a new academic hospital has been promised, with more theatres. Unfortunately, the promise was made $>10$ years ago, and it is uncertain when it will eventually be fulfilled. This unusual setting of our hospital created unnecessary cancellations of scheduled operations owing to emergencies. The cancellation rate of elective operations at $\mathrm{PBH}$ was $44.5 \%$ in a study conducted by Bhuiyan et al. ${ }^{[3]}$ more than half (64.4\%) being due to emergencies.

This study presents the mortality rate, in hospital and out of hospital within 30 days of elective procedures performed on a Saturday, and the cost incurred in overtime pay for the staff members performing the operations. During the study period, $22 \%$ of elective operations were performed on a Saturday. The 30-day mortality rate for patients operated on a Saturday was $1.5 \%(n=2)$.

Over a period of 1 year, elective operations were performed on 24 Saturdays, with an average of 6 per Saturday. There were no interruptions compared with weekdays, which were inevitably bound to cancellations because of emergencies. Therefore, it was easier to complete the Saturday list than a weekday elective list. A dedicated team and theatre were available on Saturdays to accommodate emergencies. More patients would have been assisted if operations were performed every Saturday, thus reducing the waiting period for elective operations. The addition of an elective Saturday list in our setting is a reasonable alternative, considering the lack of a daytime emergency theatre.

The weekend effect on mortality is well documented in the literature. In a study carried out at all acute and specialist hospitals in the UK for elective surgery during 3 financial years, from 2008 - 2009 to 2010 2011, the risk of death within 30 days of a planned operation increased during weekends compared with a Monday. ${ }^{[5]}$ The adjusted odds ratio (OR) for death for all elective surgical procedures was $44 \%$, and 
$82 \%$ higher if the procedures were carried out on a Friday or at the weekend, respectively. Zare et al..$^{[8]}$ found a $17 \%$ higher OR for nonemergency major surgery within 30 days of operations performed on a Friday compared with those on a Monday to Wednesday at all Veterans Affairs hospitals in the USA. Weekend admission was also associated with an increased risk of death, with an OR of $9 \%$ in the emergency setting and $32 \%$ in the elective setting in a study done in the UK by Mohammed et al. ${ }^{[1]}$

During weekends, staffing is reduced in a wide variety of structures within our hospital; hence our decision to perform operations on a Saturday for patients with $\mathrm{ASA}^{[14]}$ grade 1 , grade 2 and selected cases of grade 3. Long procedures and operations requiring intensive care unit (ICU) beds were excluded in this study.

Saturday elective surgery has an added advantage, particularly for patients who work during the week and for their families, who may want to accompany them to hospital. They consequently do not have to take additional leave if the operation is performed during a weekend. ${ }^{[15]}$ The Saturday elective operations are not interrupted, as a separate theatre is available for emergencies. In the absence of an emergency theatre during weekdays, performing elective operations on Saturdays remains a reasonable approach in an effort to reduce the elective operation waiting period.

\section{Costs of opening an elective theatre on a Saturday}

The total cost for 8 hours' work for staff members, excluding volunteer surgeons, was ZAR13 900 per Saturday, operating on an average of 6 patients (approximately ZAR2 317 per patient). In our study, surgeons were volunteers; if they were to be paid, the amount would be ZAR20 700. The calculations are based on the salary package. The calculated amount of ZAR20 700 is still much lower than the cancellation of a single patient, which was estimated at ZAR25 000. In essence, ZAR22 683 is saved for each cancellation avoided. Moreover, an operation increases patients' satisfaction, particularly if their surgery had been cancelled during the week. Each operation also brings revenue to the hospital, although it varies according to patient category of income. According to the revenue department at $\mathrm{PBH}$, patients earning ZAR55 000 per annum pay ZAR4 263 for hernia repair and for amputation, and ZAR10 040 for a mastectomy. Patients who have medical aid pay ZAR8 050 and ZAR18 505 for the same procedures, respectively.

\section{Strength and limitations of the study}

The strength of this study was that it included not only the inpatient deaths, but also the out-of-hospital deaths after the elective procedure had been performed. The limitations of the study were that not all Saturdays were used for the elective list, and that patients were followed up for 30 days. Although this is an adequate time frame to identify short-term complications, long-term complications, such as recurrence rates of conditions and development of incisional hernias, could not be captured. Patients were also not categorised into paying and non-paying groups.

\section{Conclusion}

Performing minor surgery on a Saturday has a mortality rate of $1.5 \%$ and a theatre staff cost of $\sim$ ZAR2 317 per patient, excluding surgeons' fees. If surgeons were to be paid, the costs would increase to ZAR3 450 per patient.

We recommend that Saturday elective operations be considered as an approach to maximise theatre efficiency at $\mathrm{PBH}$. This should apply to all tertiary hospitals without daytime emergency theatres and/or long waiting periods, but should exclude high-risk patients.

We recommend that where human and financial resources are available, a comparative study of weekday and Saturday elective operations be conducted to determine if operating on patients on a Saturday puts them at higher risk of death than surgery during the week.

Acknowledgement. We are grateful to Mr Joseph Wamukuo, health economist, for his valuable comments with regard to this manuscript.

Author contributions. MMZUB and RM conceptualised the research question, drafted the protocol and manuscript and contributed to the final drafts of the protocol and manuscript.

Funding. None.

Conflicts of interest. None.

1. Meara JG, Leather AJM, Hagander L, et al. Global surgery 2030: Evidence and solutions for achieving heath, welfare and economic development. Lancet 2015;386(9993):569-624. https://doi.org/10.1016/ S0140-6736(15)60160-X

2. Bloom J. 1629 patients on surgery waiting list at Steve-Biko. Surgery crisis as ops cancelled at Steve-Biko. 2012. politicsweb.co.za/politics/1-629-patients-on-surgery-waiting-list-at-steve-bi (accessed 15 December 2017).

3. Bhuiyan MMZU, Mavhungu R, Machowski ZA. Provision of emergency theatre in tertiary hospitals is cost effective: Audit and cost of cancelled planned elective operations of general surgical patients in

Pietersburg Hospital. S Afr Med J 2017;107(3):239-242. https://doi.org/10.7196/SAMJ.2017.v107i3.1068

McIsaac DI, Bryson GL, van Walraven C. Elective, major noncardiac surgery on the weekend: population-based cohort study of 30-day mortality. Med Care 2015;53(6):560-567. https://doi.
org/10.1097/MRL0000000000000137

org/10.1097/MRL0000000000000137
Aylin P, Alexandrescu R, Jen MH, et al. Day of week of procedure and 30 day mortality for elective surgery: Retrospective analysis of hospital episode statistics BMJ 2013;346:f2424. https://doi.org/10.1136/ bmj.f2424

6. Bell CM, Redelmeier DA. Mortality among patients admitted to hospitals on weekends as compared with weekdays. N Engl J Med 2001;345(9):663-668. https://doi.org/10.1056/NEJMsa003376

Vest-Hansen B, Riis AH, Sorensen HT, Christiansen CF. Out-of-hours and weekend admissions to Danish medical departments: Admission rates and 30-day mortality for 20 common medical conditions. BMJ Open 2015;5(3):e006731. https:///doi.org/10.1136/bmjopen-2014-006731

8. Zare MM, Itani KMF, Schifftner TL, et al. Mortality after nonemergent major surgery performed on Friday versus Monday through Wednesday. Ann Surg 2007;246(5):866-874. https://doi.org/10.1097/ SLA.0b013e3180cc2e60

9. Kostis WJ, Demissie K, Marcella SW, et al. Weekend versus weekday admission and mortality from myocardial infarction. N Engl J Med 2007;356(11):1099-1109. https://doi.org/10.1056/NEJMoa063355

10. McCrory MC, Gower EW, Simpson SL, et al. Off-hours admission to pediatric intensive care and mortality. Pediatrics 2014;134(5):e1345-el353. https://doi.org/10.1542/peds.2014-1071

11. Mohammed MA, Sidhu KS, Rudge G, Stevens AJ. Weekend admission to hospital has a higher risk of death in the elective setting than in the emergency setting: A retrospective database study of national health service hospitals in England. BMC Health Serv Res 2012;12:87. https://doi.org/10.1186/14726963-12-87

2. Schumulewitz L, Proudfoot A, Bell D. The impact of weekends on outcome for emergency patients. Clin Med 2005;5(6):621-625. https://doi.org/10.7861/clinmedicine.5-6-621

13. Worni M, Østbye T, Gandhi M, et al. Laparascopic appendisectomy outcomes on the weekend and during Wo week are no different: A national study of 151774 patients. World J Surg 2012;36:1527-1533. https://
the doi.org/10.1007/s00268-012-1550-z

14. Sankar A, Johnson SR, Beattie WS, et al. Reliability of the American Society of Anaesthesiologists physical status scale in clinical practice. Br J Anaesh 2014;113(3):424-432. https://doi.org/10.1093/bja/aeul00

Ir J Med Sci 2004;173(3):133-135.

Accepted 21 September 2017. 